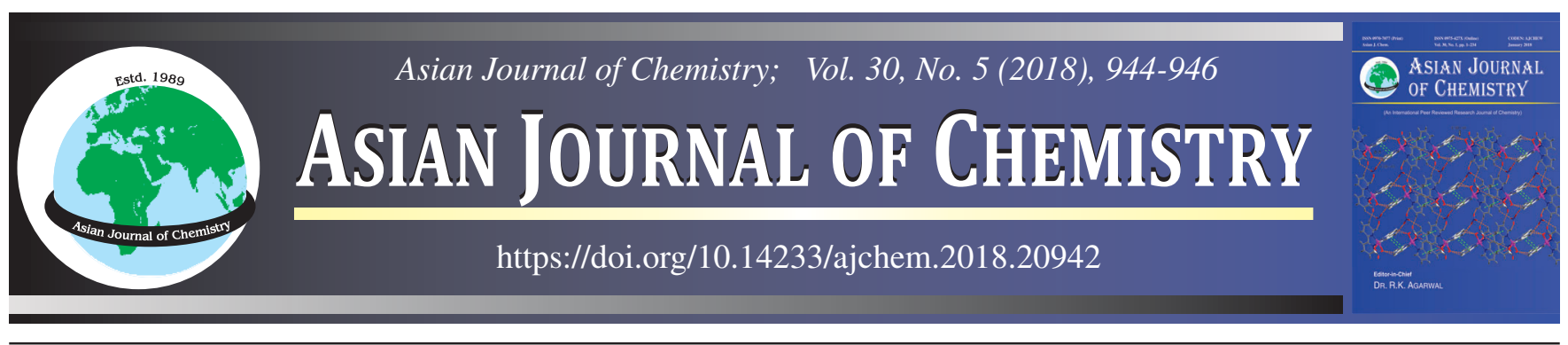

\title{
Preliminary Studies of Activated Carbon Properties on Bagasse (Saccharum officinarum) as Adsorbent to the Purification Process of Used Cooking Oil
}

\author{
Agus Kembaren, Moondra Zubir ${ }^{*}$, Jasmidi and Albinus Silalahi
}

Department of Chemistry, Faculty of Mathematics and Natural Science, State University of Medan, Medan, North Sumatera, Indonesia

*Corresponding author: Tel: +62 85262736484; E-mail: moondrazubir@unimed.ac.id

\section{INTRODUCTION}

Activated carbon was synthesized from all natural ingredients which contain carbon, both of organic and inorganic carbon on the condition that the material has a porous structure like Agassi. The adsorption capacity is depended on the particle surface area and this ability can be enhanced when the activated carbon is activated by chemicals (chemical activation) or by heating at high temperature (physical activation). So far, the synthesis of bagasse has a limited use in animal feed, raw material for fertilizer and fuel boiler in the sugar-processing plant. Currently, because the usage of bagasse has low economic value, it has become necessary to develop technology for utilization of this waste and utilization of Agassi as bioadsorbent.

Pelican et al. [1] reported the usage of bagasse for As(V) adsorption in water. Mohan and Singh [2] also reported cane as an adsorbent for the removal of heavy metals in water. Wannahari and Nordin [3] used bagasse as an adsorbent for the initial treatment of used cooking oil for biodiesel feedstock. Bagasse is usually thrown away at the shops selling sugarcane juice. Due to high amount of cellulose content in bagasse, it has the potential to be used as activated carbon.

Rapid population growth and the development of the hospitality industry, restaurants and fast food businesses have exponentially increased the demand of cooking oil. Usage of cooking oil at high temperatures and reusability usage induce the degradation reactions occur which degrade the quality of cooking oil, so the oil cannot be re-used and must be discarded.

In this study, bagasse from sugarcane juice vendor at HM Yamin Street in Medan City will be transformed into activated carbon. Activated carbon will then be used to purify the used cooking oil obtained from sellers of fried food in the same location. So, purified cooking oil is expected to be reused or become raw material for the manufacturing of biodiesel. Thus, bagasse waste and used cooking oil can be converted into a more useful product. The specific objective of this study was to characterize activated carbon made from bagasse and then used it as an adsorbent in the purification of used cooking oil.

\section{EXPERIMENTAL}

Materials used in this study includes the used cooking oil which was procured from HM Yamin Street of Medan City, North Sumatra, Indonesia and bagasse from the waste of milling cane juice in Sentosa Baru street, Medan City, North Sumatra, Indonesia. Other materials used in the study include ethanol (96\%), $\mathrm{H}_{3} \mathrm{PO}_{4}$, glacial acetic acid, chloroform, potassium iodide, starch indicator, $\mathrm{Na}_{2} \mathrm{~S}_{2} \mathrm{O}_{3}, \mathrm{KOH}$ and a phenolphthalein indicator.

Activated carbon preparation: This preparation procedure was obtained from the literature [4]. Bagasse obtained 
from the remnants of milling cane juice is first washed and then dried under sunlight. Dried bagasse is then cut into smaller parts and dried in the furnace until it becomes charcoal. Charcoal is milled in porcelain and sifted with a 200 mesh sieve size. The activation process is carried out using $1 \mathrm{M} \mathrm{H}_{3} \mathrm{PO}_{4}$ with a ratio of active carbon:acid phosphate as $1: 2$ and then the mixture is stirred and allowed to stand for $90 \mathrm{~min}$. It is then heated at temperatures of 300,350 and $400{ }^{\circ} \mathrm{C}$ for $1 \mathrm{~h}$. After the end of the activation process, the mixture is then cooled and washed with distilled water to remove residual acid until $\mathrm{pH}$ reaches 7. The adsorbent is dried in an oven at $110{ }^{\circ} \mathrm{C}$ for $1 \mathrm{~h}$ and then cooled in a desiccator.

Activated carbon properties measurement: The quality test of activated carbon then reviews moisture, volatile matter content and ash content as per the Indonesian National Standard of SNI 06-3730-1995.

Used cooking oil preparation: The used cooking oil is then filtered with cheesecloth to remove impurities such as solids or leftover frying. The sample is then analyzed for water content in the oil, the rate of free fatty acids (FFA) and peroxide number as per the Indonesian National Standard of SNI 013741-2013.

Purification of used cooking oil: The purification procedure detailed in this study refers to the one done by Sholikhah et al. [5]. Now, $100 \mathrm{~g}$ of oil is then put into the beaker glass and heated at $90{ }^{\circ} \mathrm{C}$. Then, activated carbon $(6 \mathrm{~g})$ is mixed in the oil and stirred with a magnetic stirrer for $90 \mathrm{~min}$. Then, the filtrate is collected and determined for the water content, free fatty acids and peroxide number. The same procedure is followed for 8 and $10 \mathrm{~g}$ activated carbon [5].

\section{RESULTS AND DISCUSSION}

Synthesized activated carbon is characterized by the properties such as moisture, volatile matter content and ash content as per the Indonesian National Standard procedure of SNI 06-3730-1995. The water content analysis is done to calculate the remaining water content in the activated carbon after the activation process with the activator agent. The results showed that the highest water content is $22.53 \%$ when heated at $300{ }^{\circ} \mathrm{C}$ and low water content is $3.14 \%$ when heated at 450 ${ }^{\circ} \mathrm{C}$. The result indicates that the water content is removed during the heating at high temperature. Based on the Indonesian National Standard of SNI 06-3730-1995, the maximum of the activated carbon water content is $15 \%$. It confirms that the activated carbon prepared by heating at 350 to $450{ }^{\circ} \mathrm{C}$ corresponds to this standard (Fig. 1).

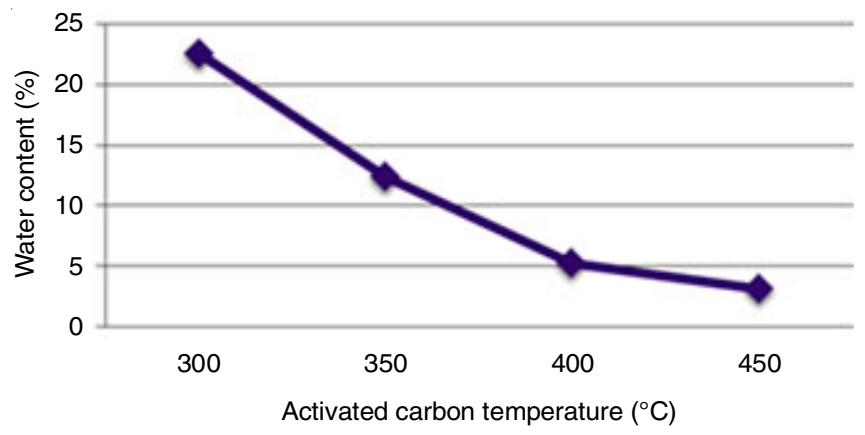

Fig. 1. Activated carbon temperature dependence on water content
Determination of the ash content aims to examine the amount of the oxide in the activated carbon. The high content of oxide indicates the higher ash content of the activated carbon (Fig. 2). The volatile substance content analysis was determined to examine the amount of a substance or compound which cannot be evaporated in the process of carbonization and activation. Activated carbon heating influence dependence to volatile substance showed in Fig. 3. Increasing the temperature during activation produces the lower amount of volatile substance. It indicates that the higher temperature helps in the conversion carbon to $\mathrm{CO}_{2}$.

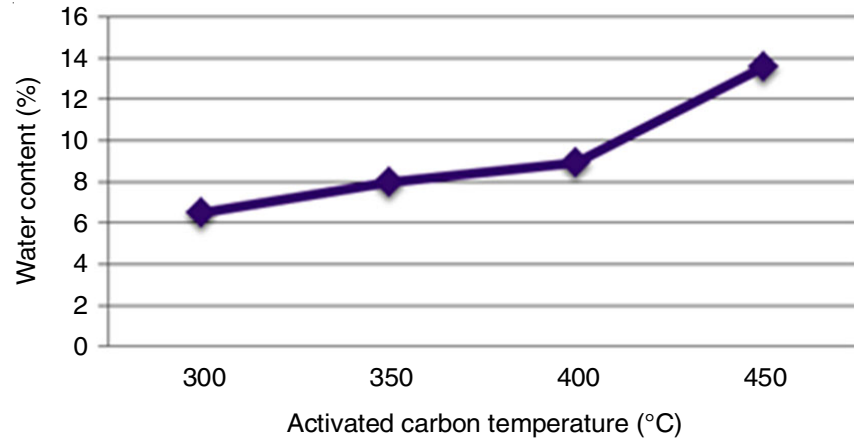

Fig. 2. Activated carbon temperature independence on ash content

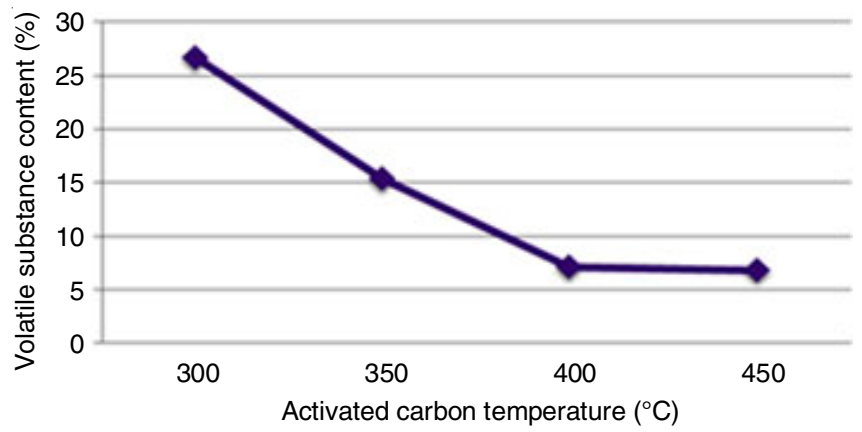

Fig. 3. Activated carbon temperature independence on volatile substance content

The free fatty acid analysis showed the lowest free fatty acid content in purified oil, which adsorbed on activated carbon at $400{ }^{\circ} \mathrm{C}$ and $10 \mathrm{~g}$ adsorbent weight. The highest free fatty acid is observed in the oil which adsorbed on activated carbon at $300^{\circ} \mathrm{C}$ and $6 \mathrm{~g}$ adsorbent weight. The amount of the activated carbon used in the adsorption process affects to fatty acid content of the used cooking oil. The higher amount of activated carbon was added, increasing the amount of free fatty acids and affect to lower free fatty acid content.

The content of free fatty acids in cooking oil is $0.5 \%$ as per the Indonesian National Standard. However, the treatment by adsorption using activated carbon produce more proper the bagasse oil regeneration and can be used for other purposes, because oil regeneration produce smaller free fatty acid value $(\leq 0.5 \%)$. Fig. 4 shows free fatty acid enhance by increasing the amount of activated carbon and higher of activated carbon temperature induce to lower free fatty acid content. Otherwise, the high temperature of activated carbon gives a negative impact, because it can induce the increasing of free fatty acid formation. 


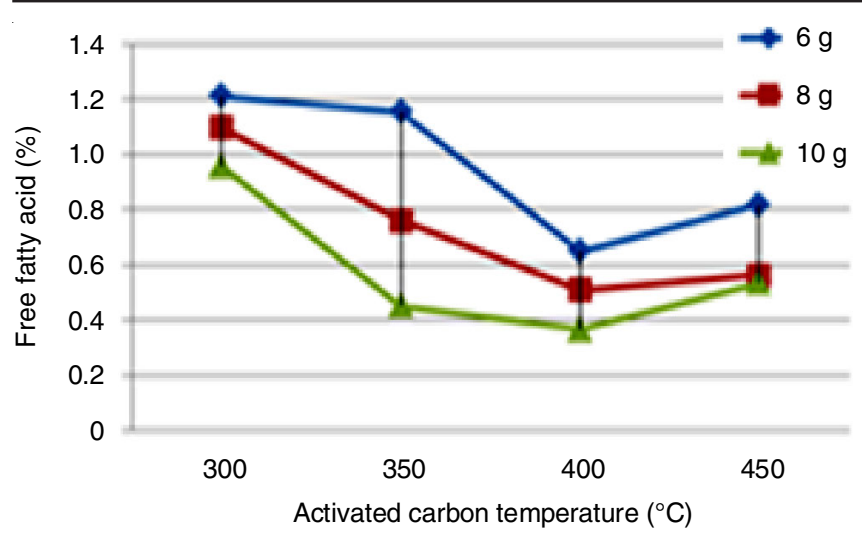

Fig. 4. Activated carbon temperature dependence on free fatty acid content at different quantities of activated carbon

According to Ozgul and Turkay [6], the functional group of an organic compound influences the adsorption affinity. Minyu and Proctor [7] also reported that organic compounds contain the acid functional group, which adsorbs well on polar surfaces. Activated carbon which chemical activated expected as polar as can absorb free fatty acids such as the carbolic acid. It is supported by Ozgul and Turkay [6], the reduction percentage of free fatty acid content is higher than the reduction percentage of methyl ester in the same treatment, the process of adsorption by rice husk ash as an adsorbent. However, carboxylic acid compound adsorption affinity is higher than the affinity adsorption properties of ester compounds [8].

Damage to oil in this study was determined by using the peroxide parameter. Peroxide is the initial product in a breakdown of cooking oil due to oxidation in the heating process [9]. Higher number of peroxide shows the extent of damage to the oil and oil will soon undergo rancidity. According to the Indonesian National Standard (01-2901-2006), the maximum of cooking oil peroxide is $10 \mathrm{meq} / \mathrm{kg}$. Fig. 5 shows that the adsorbent is used to reduce the content of peroxide compounds in cooking oil. Absorptivity of peroxide component in used cooking oil by activated carbon due to the presence of silanol formed from $\mathrm{SiO}_{2}$ [10]. The hydrogen atom of silanol group binds to peroxide group on the peroxide compound, so that peroxide molecules can be adsorbed on the surface of adsorbent through hydrogen bonding [2]. On the other hand, Agassi in activation with polar acid has high affinity to polar solute. Peroxide compounds present in the oil as polar are easily absorbed by the cellulose of Agassi [11]. It causes the adsorbent of Agassi to reduce levels of peroxide value in the used cooking oil.

The cooking oil quality requirements according to the Indonesian National Standard of 01-2901-2006, for peroxide (maximum $10 \mathrm{meq} / \mathrm{kg}$ ), indicate that the used cooking oil has been damaged and is not suitable for consumption because of the high levels of peroxide $(47.9119 \mathrm{meq} / \mathrm{kg})$. The regeneration process by using adsorbents of Agassi can significantly decrease the peroxide content of the used cooking oil, but activated

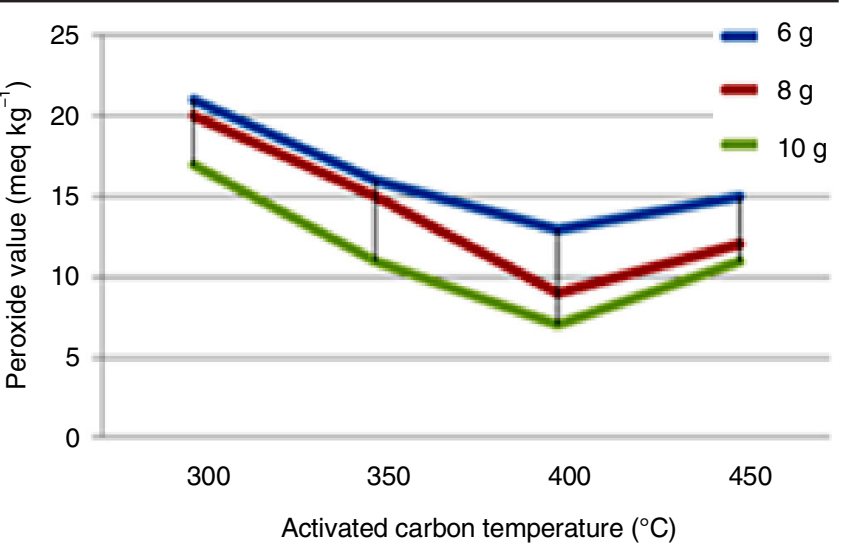

Fig. 5. Activated carbon temperature dependence on peroxide content at different quantities of activated carbon

carbon temperature of $400{ }^{\circ} \mathrm{C}$ produces the lowest peroxide, in particular on the addition of the adsorbent as much as $10 \mathrm{~g}$ is equal to $(6.9939 \mathrm{meq} / \mathrm{kg})$.

\section{Conclusion}

This study concludes that activated carbon activation temperature significantly influences the refining process of used cooking oil. Increasing the activation temperature enhances the reduction of free fatty acids and peroxide content in the used cooking oil, but the temperature $\geq 450{ }^{\circ} \mathrm{C}$ reduces the adsorption capacity of the adsorbent. The amount of active carbon used in the adsorption process greatly affects the quality of the oil, that is, the higher amount of activated carbon in adsorption process decreases the amount of free fatty acid and peroxide content in the used cooking oil.

\section{REFERENCES}

1. E. Pehlivan, H.T. Tran, W.K.I. Ouédraogo, C. Schmidt, D. Zachmann and M. Bahadir, Food Chem., 138, 133 (2013); https://doi.org/10.1016/j.foodchem.2012.09.110.

2. D. Mohan and K.P. Singh, Water Res., 36, 2304 (2002); https://doi.org/10.1016/S0043-1354(01)00447-X

3. R. Wannahari and M.F.M. Nordin, Am. J. Eng. Appl. Sci., 5, 59 (2012); https://doi.org/10.3844/ajeassp.2012.59.62.

4. A. Geethakarthi and B.R. Phanikumar, Int. J. Water Environ. Sci. Eng., 8, 561 (2011);

https://doi.org/10.1007/BF03326242.

5. N.S. Suharty, B. Wirjosentono, M. Firdaus, D.S. Handayani, J. Sholikhah and Y.A. Maharani, J. Phys. Sci., 19, 105 (2008).

6. S. Özgül-Yücel and S. Türkay, J. Am. Oil Chem. Soc., 80, 81 (2003); https://doi.org/10.1007/s11746-003-0655-7.

7. J. Minyu and A. Proctor, J. Am. Oil Chem. Soc., 70, 575 (1993); https://doi.org/10.1007/BF02545322.

8. H. Ruiz, M. Zambtrano, L. Giraldo, R. Sierra and J.C. Moreno-Pirajan, Orient. J. Chem., 31, 753 (2015).

https://doi.org/10.13005/ojc/310217.

9. E. Choe and D.B. Min, Comprehen. Rev. Food Sci. Food Safety, 5, 169 (2006); https://doi.org/10.1111/j.1541-4337.2006.00009.x

10. W. Zschau, Eur. J. Lipid Sci. Technol., 103, 505 (2001); https://doi.org/10.1002/1438-9312(200108)103:8<505::AIDEJLT505>3.0.CO;2-7.

11. J. Pokorny, Grasas y Aceites, 49, 265 (1998). 